\title{
Consistent Commitment: Patterns of Engagement across Time in Massive Open Online Courses (MOOCs)
}

\author{
Rebecca Ferguson and Doug Clow \\ Institute of Educational Technology, The Open University, UK \\ Rebecca.Ferguson@open.ac.uk
}

\begin{abstract}
Massive open online courses (MOOCs) are being used across the world to provide millions of learners with access to education. Many who begin these courses complete them successfully, or to their own satisfaction, but the high numbers who do not finish remain a subject of concern. In 2013, a team from Stanford University analyzed engagement patterns on three MOOCs run on the Coursera platform. They found four distinct patterns of engagement that emerged from MOOCs based on videos and assessments. Subsequent studies on the FutureLearn platform, which is underpinned by social-constructivist pedagogy, indicate that patterns of engagement in these massive learning environments may be influenced by decisions about pedagogy and learning design. This paper reports on two of these studies of learner engagement with FutureLearn courses. Study One first tries, not wholly successfully, to replicate the findings of the Coursera study in a new context. It then uses the same methodological approach to identify patterns of learner engagement on the FutureLearn platform, and explores how these patterns may have been influenced by pedagogy and elements of learning design. Study Two investigates whether these patterns of engagement are stable on subsequent presentations of the same courses. Two patterns are found consistently in this and other work: samplers who visit briefly, and completers who fully engage with the course. The paper concludes by exploring the implications for both research and practice.
\end{abstract}

\section{$1 \quad$ INTRODUCTION}

The generic name for MOOCs emphasizes their commonalities of scale (massive), economic/philosophical perspective (open), location (online), and structure (course). At the same time, it omits a key area of difference, their underlying pedagogy, which can also be described as their approach to teaching and learning and their understanding of how learning takes place.

The original MOOCs, developed by Siemens and Downes from 2008 onwards, employed a connectivist approach to learning (Downes, 2012). This approach is signalled by references to them as cMOOCs. Connectivism considers learning to be social, technologically enhanced, distributed within a network and associated with the recognition and interpretation of patterns (Siemens, 2005). Knowledge is developed as a result of experience and the self-organizing nature of appropriately designed networks (Downes, 2012).

The cMOOCs were followed by xMOOCs. In this case, the defining letter " $x$ " did not refer to a specific pedagogy, but to the role of these MOOCs as an extension to a previous offering. However, in many cases, this "extension" version took the essential elements of education to be content and assessment, with input from educators bundled as part of the content. This led to an instructivist approach to teaching and 
(2015). Consistent commitment: Patterns of engagement across time in Massive Open Online Courses (MOOCs). Journal of Learning Analytics, 2(3), 55-80. http://dx.doi.org/10.18608/jla.2015.23.5

learning in which "learning goals are predefined by an instructor, learning pathways structured by environment and learners have limited interactions with other learners" (Littlejohn, 2013). In Siemens' view, "cMOOCs focus on knowledge creation and generation whereas XMOOCs focus on knowledge duplication" (Siemens, 2012).

This binary distinction between $\mathrm{CMOOCS}$ and $\mathrm{xMOOCs}$ was useful when the first $\mathrm{xMOOCs}$ appeared, but has become less relevant as new MOOC platforms and course developers have emerged. The FutureLearn platform, launched in 2013, employs a social-constructivist pedagogy, based on the Conversational Framework (Laurillard, 2002; Pask, 1976). This is a general theory of effective learning through conversations, with oneself and others, about the immediate world and about abstract concepts (Ferguson \& Sharples, 2014). To engage in successful conversations, all parties need access to a shared representation of the subject matter as well as tools for commenting, responding, and reflecting, and so these tools and shared representations formed part of the design of the FutureLearn platform.

Although different types of MOOCs have different pedagogies, a problem that most of them experience is the large difference between numbers registering and numbers completing. Some of this drop-off can be explained in positive ways. MOOC registration can be regarded as similar to bookmarking a college website, sending off for a course prospectus, or placing a textbook temporarily in an online shopping basket - it does not necessarily represent a commitment to engage further with learning in that context. FutureLearn reports that around a third of those who register do not return to start the course. This suggests it is more useful to compare the number of learners starting a course with the number of learners who complete, rather than taking the number of people who register as the baseline.

Up to a third of those who "drop out" may have clicked the "Register" button with little or no intention of completing - or even starting - the course. Another large group, characterized as "Samplers," appears to be made up of those who take a brief look at a course, decide it is not for them, and then leave (Kizilcec, Piech, \& Schneider, 2013). Respondents to surveys associated with FutureLearn MOOCs have shared various reasons for participating, including trying out learning online, finding out more about MOOCs, or finding out more about a specific university. The learning objectives of these learners may be met without working through an entire course.

Another perspective is offered by Downes, who points out that most media are not consumed in their entirety by any single individual: "It's actually very rare to find media of any sort that is intended to be consumed in its entirely. Most of the time, in most things, we pick and choose what is important to us. That is the normal mode of interacting with content [...] nobody thinks a library a failure if you don't read everything in the collection, or an author a failure if you don't read their entire corpus. And just so with MOOCs" (Downes, 2014).

Despite these valid reasons and explanations for non-completion, the high dropout rates on most MOOCs still provide cause for concern. MOOCs are open, but "students seek not merely access, but access to 
(2015). Consistent commitment: Patterns of engagement across time in Massive Open Online Courses (MOOCs). Journal of Learning Analytics, 2(3), 55-80. http://dx.doi.org/10.18608/jla.2015.23.5

success" (Daniel, 2012) and it seems that many encounter not success but failure when they study these courses. The steep drop-off of the "Funnel of Participation" (Clow, 2013), which shows similar declines in engagement across different types of online learning sites, is not welcomed by all.

Jordan's work (Jordan, 2014a) provides an overview of this issue, and her website (Jordan, 2014b) provides a dynamic view of the data about MOOC completion rates that has been made public. The site currently presents data relating to around 220 MOOCs based on a variety of different platforms. The site deals with the percentage of registered learners who complete a course (rather than the percentage of people who actually started the course who go on to complete). It shows that MOOCs typically report completion rates of around $15 \%$. At the time of writing, no MOOC with more than 60,000 registered students had reported a completion rate of higher than $13 \%$, and only three MOOCs had achieved a completion rate of over $40 \%$. However, these high-performing outliers suggest that we should not be satisfied with MOOC current completion rates, because higher ones are possible.

This variability in figures suggests that course context, course design and course pedagogy have an effect on retention, and thus on students' chances of success.

\subsection{Using Analytics to Investigate MOOCs}

Learning analytics are concerned with the use of trace data relating to learners and their contexts, for purposes of understanding and optimizing learning and the environments in which it occurs (SoLAR, 2011). They therefore offer a way of identifying factors that influence retention, enabling educators and platform providers to make changes to context, design, and pedagogy where appropriate. The large datasets generated by $\mathrm{MOOC}$ activity provide a strong basis for this type of approach.

Kop and colleagues looked at engagement patterns on the PLENK2010 connectivist MOOC (Kop, Fournier, \& Sui Fai, 2011). As this type of MOOC links a network of tools and resources, it is difficult to track all activity, but their conclusion was that 40-60 of the 1,641 learners registered on the course contributed actively on a regular basis, and that this engagement supported positive learning outcomes. The visible participation rate of others was much lower, indicating a consuming behaviour. This division between the Visible Contributors and the Consumers signalled that there are different ways of interacting on a MOOC. Milligan and colleagues investigated patterns of engagement in connectivist MOOCs and identified three distinct types of engagement: Active Participation, Passive Participation, and Lurking (Milligan, Littlejohn, \& Margaryan, 2013). These classifications are strongly associated with connectivist pedagogy and to MOOCs that are structured to enable learners to construct knowledge together so are less relevant to courses in which key elements are pre-defined course content and assessment.

In 2013, Kizilcec, Piech, \& Schneider analyzed patterns of engagement and disengagement in three MOOCs on the Coursera platform. Two understandings underpinned this analysis. One was the view that "learning is a process of individual knowledge construction." The second was the view that the principal 
(2015). Consistent commitment: Patterns of engagement across time in Massive Open Online Courses (MOOCs). Journal of Learning Analytics, 2(3), 55-80. http://dx.doi.org/10.18608/jla.2015.23.5

features of these courses were video lectures and assessments. This analysis found four patterns of engagement with these courses:

- $\quad$ Completing: These learners completed the majority of assessments.

- $\quad$ Auditing: These learners watched most of the videos but completed assessments infrequently, if at all.

- Disengaging: These learners completed assessments at the start of the course, then reduced their engagement.

- $\quad$ Sampling These learners explored some course videos.

As these clusters were found consistently across three MOOCs, each targeted at students working at a different educational level, it appeared plausible that they could be applied to other courses and that "MOOC designers can apply this simple and scalable categorization to target interventions and develop adaptive course features" (Kizilcec, Piech, \& Schneider, 2013). This Coursera study has proved to be very influential. Not only is it highly cited within the academic literature but also the terms it uses are widely applied when describing and planning for MOOC engagement.

However, the generalizability of these categories is qualified on the grounds that these classifications "would make sense in any MOOC that is based on videos and assessments" (Kizilcec, Piech, \& Schneider, 2013). This suggests that these categories may only be applicable to courses using pedagogies based on course content and on the use of either formative or summative assessment.

In this paper, we investigate whether the same patterns of engagement are found in MOOCs that employ social constructivist pedagogy (Study One), or if other patterns of engagement apply. We also investigate whether patterns of learner engagement in MOOCs are stable across multiple presentations of the same course (Study Two).

In social-constructivist MOOCs, knowledge is jointly constructed through conversation. Contributing to or reading discussion comments is therefore an important part of the learning process. In these cases, three elements should be taken into account: 1) active engagement with course content, 2) active engagement with course assessment, and 3) active engagement with course discussion.

\subsection{Replication}

Within the hard sciences, replication of previously published work is routine. Within the social sciences, it is unusual. Recent efforts to attempt to replicate key findings in social psychology have been controversial (Bohannon, 2014). There has been significant replication work in the Educational Data Mining field, particularly the body of work associated with the Pittsburgh Science of Learning Center's DataShop. ${ }^{1}$

\footnotetext{
${ }^{1}$ http://www.learnlab.org/technologies/datashop/
} 
However, outside the context of cognitive tutors and similar fine-grained analysis, replication work in learning analytics is very unusual, as far as we are aware. As an empirical discipline, we believe that the field of learning analytics is well placed to use such rigorous approaches. To be clear, we regard the work of Kizilcec and colleagues as important and interesting, and in the studies reported here we are seeking to test how robust their findings are in a different context.

\section{FUTURELEARN DATASET}

In order to investigate patterns of engagement within MOOCs employing social-constructivist pedagogy, we used data provided by FutureLearn. This company, owned by The Open University, is currently in partnership with fifty universities, sixteen specialist organizations, and six centres of excellence to deliver free online courses. The company has developed a new MOOC platform based on scalable web technology and underpinned by a social-constructivist pedagogy (Sharples \& Ferguson, 2014). Each teaching element (step) is associated with a free-flowing discussion. These are intended to emulate a "water cooler discussion" about the immediate content. As with conversations around an office water cooler, people come and go, nobody is expected to engage throughout, but there can be a continuous sense of lively interaction. Typically, the discussion associated with any step on a FutureLearn MOOC will attract hundreds, thousands, or even tens of thousands of contributions, with "Like" and "Follow" options providing ways of navigating these.

\subsection{Study One: Identifying Patterns of Engagement}

Each FutureLearn partner institution has access to data related to courses they run. In Study One, designed to identify patterns of engagement in FutureLearn MOOCs, we therefore focused our attention on data from four MOOCs run by our institution, The Open University. The data on platform activity are not directly associated with demographic data (as discussed below), and so the figures for gender balance presented in Table 1 are taken from responses to the start-of-course survey for each course. These four MOOCs ran soon after the launch of FutureLearn, at a point when the majority of marketing was taking place within the UK, so the majority of participants on each course were based in the UK.

The number of participants reported in Table 1 indicates the number of individuals - both educators and learners - who appeared in our Study One dataset because they were active on the platform after the start date of the course. People active before the start date were removed from the dataset entirely, because the only people with access at that point were educators or FutureLearn staff. In FutureLearn terms, a Fully Participating learner is one who marked a majority of the course steps complete and completed all the assessments. 
(2015). Consistent commitment: Patterns of engagement across time in Massive Open Online Courses (MOOCs). Journal of Learning Analytics, 2(3), 55-80. http://dx.doi.org/10.18608/jla.2015.23.5

Table 1: Overview of dataset for Study One

\begin{tabular}{c|rrrr}
\hline & MOOC1 & MOOC2 & MOOC3 & MOOC4 \\
\hline Subject area & Physical Sciences & Life Sciences & Arts & Business \\
M & $51 \%$ & $39 \%$ & $32 \%$ & $35 \%$ \\
F & $48 \%$ & $61 \%$ & $67 \%$ & $65 \%$ \\
Participants & 5,069 & 3,238 & 16,118 & 9,778 \\
Fully Participating & 1,548 & 684 & 3,616 & 1,416 \\
Participation Rate & $31 \%$ & $21 \%$ & $22 \%$ & $14 \%$ \\
\hline
\end{tabular}

Each of these MOOCs specified that no previous experience of studying the subject was required. However, the Arts MOOC3 was recommended for learners aged $16+$, due to the possibility that discussion content might include material that would be inappropriate for minors. Fully Participating learners on these MOOCs could gain a Statement of Participation for a fee, but no credits were awarded and participants were not required to complete assessments by a certain date. As a result, the "finished assessment on time" and "finished assessment late" classifications were of less relevance than on the Coursera study (Kizilcec, Piech, \& Schneider, 2013). Coursera course content focuses on videos. While FutureLearn courses also include videos, they make use of substantial quantities of other learning material, predominantly discussion and text with pictures.

The different context of Coursera and FutureLearn affected the raw data accessible to us as analysts. Kizilcec and colleagues were able to obtain full log data, assessment scores, demographic data, and survey responses, all at an individual learner level. This enabled them to report some interesting correlations. On early FutureLearn MOOCs, demographic, survey, and activity data were not linked by personal identifiers, so we had access to demographic and survey data only at a summary level for the courses we were researching. We were able to obtain individual-level activity data, which were anonymized before we received them. As well as assigning random IDs, this process partially aggregated the activity data, so we only had access to the date and time of a learner's first visit to a step, not the date or time of any subsequent visits. Graphical inspection of these data suggested that there were no gross differences in activity patterns compared to what one would expect in more traditional logfile analysis, although this change has had some effects, which we note where they arise.

\section{CLUSTERING}

\subsection{Replicating the Method}

Our initial approach in Study One followed the one applied in the Coursera study as far as possible, in order to investigate whether previous findings could be replicated in a different context. That study adopted a methodology set out in Kizilcec, Piech, and Schneider (2013), designed to identify a small number of ways in which learners interact with MOOCs. 
(2015). Consistent commitment: Patterns of engagement across time in Massive Open Online Courses (MOOCs). Journal of Learning Analytics, 2(3), 55-80. http://dx.doi.org/10.18608/jla.2015.23.5

Kizilcec and his colleagues began by computing a description for individual learners of the way in which they engaged in each assessment period of the course (typically a week), and then applied clustering techniques to find subpopulations in these engagement descriptions. FutureLearn courses are divided into weeks and, although there is no compulsion to work through at the same pace as others, an overview of the data showed that activity did indeed follow a weekly cycle, spiking after the weekly course email was sent out each Monday (see Figure 1). Underlying the spikes, there was a general falling-off in activity over time, as would be expected in a MOOC (Clow, 2013). It is possible, however, that our measure of activity (time of first visit to each piece of content) masked later activity because re-visits to content visited earlier were not counted, and so Figure 1 is likely to over-state the fall-off in activity.

We therefore followed the Coursera study and computed a description for each learner based on individual activity in a course week. Their "engagement descriptions" have six or eight elements, because each course ran for six or eight weeks.

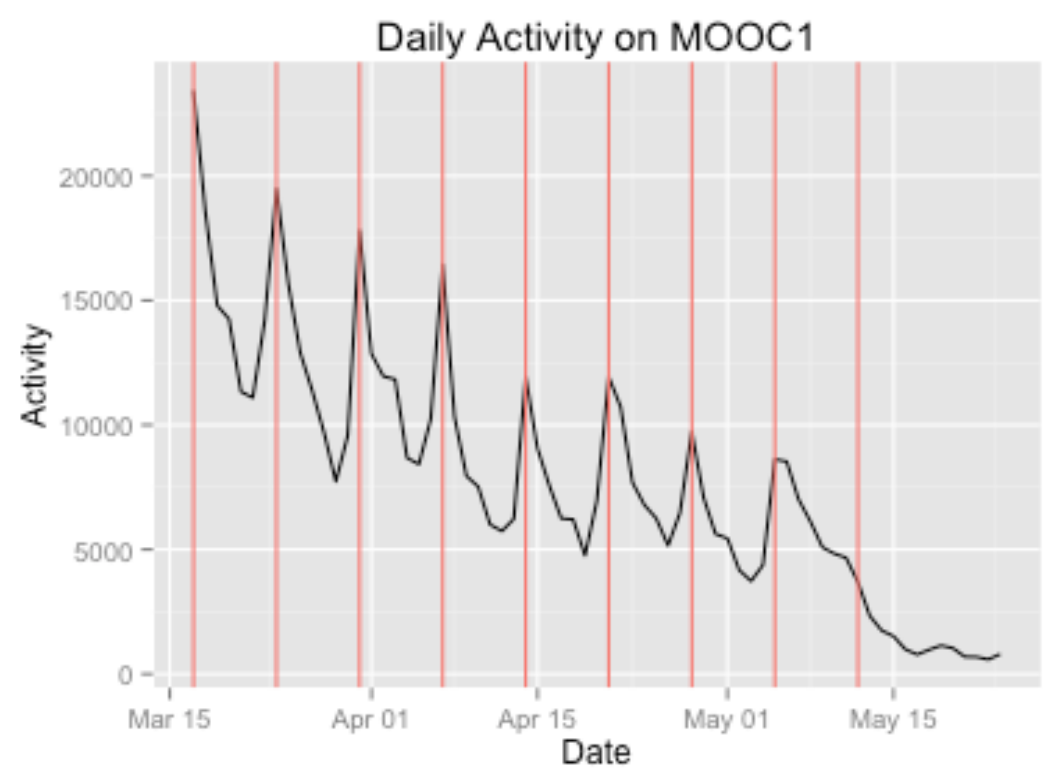

Figure 1: Activity on Study One, MOOC1.

Dark red vertical lines show the date of the weekly course email.

As in the Coursera study, students' activity in each week was assigned to one of four categories:

- $\quad$ "T = on track" if they undertook the assessment on time

- $\quad$ " $B=$ behind" if they submitted the assessment late

- $\quad$ " $\mathrm{A}=$ auditing" if they engaged with content but not with the assessment

- $\quad$ "O = out" if they did not participate.

Although FutureLearn students were not required to submit assessed work by a particular date, we retained these classifications and counted an assessment as submitted "late" if it was completed after the 
end of the course week. For example, if a learner missed the first week of a course (out), submitted assessments on time in weeks 2-6 (on track), submitted week 7's assessment in week 8 (behind), and then engaged with content only in week 8 (auditing), their engagement profile during this section of the study would appear as $[\mathrm{O}, \mathrm{T}, \mathrm{T}, \mathrm{T}, \mathrm{T}, \mathrm{T}, \mathrm{B}, \mathrm{A}]$.

Once we had created engagement profiles for each Study One learner in this way, we followed the method of Kizilcec's team and applied the k-means clustering algorithm to partition the learners into a small number of groups. To cluster engagement patterns, a numerical value for the dissimilarity between them is required. There are several possibilities for this, but in this initial exploration, we followed their approach: we first assigned numerical values to each label (On Track =3, Behind = 2, Auditing = 1, Out $=$ $0)$. We then calculated the $L_{1}$ norm for each engagement pattern and used that as the basis for onedimensional $k$-means clustering, thus minimizing the sum of the differences between individual patterns in each cluster.

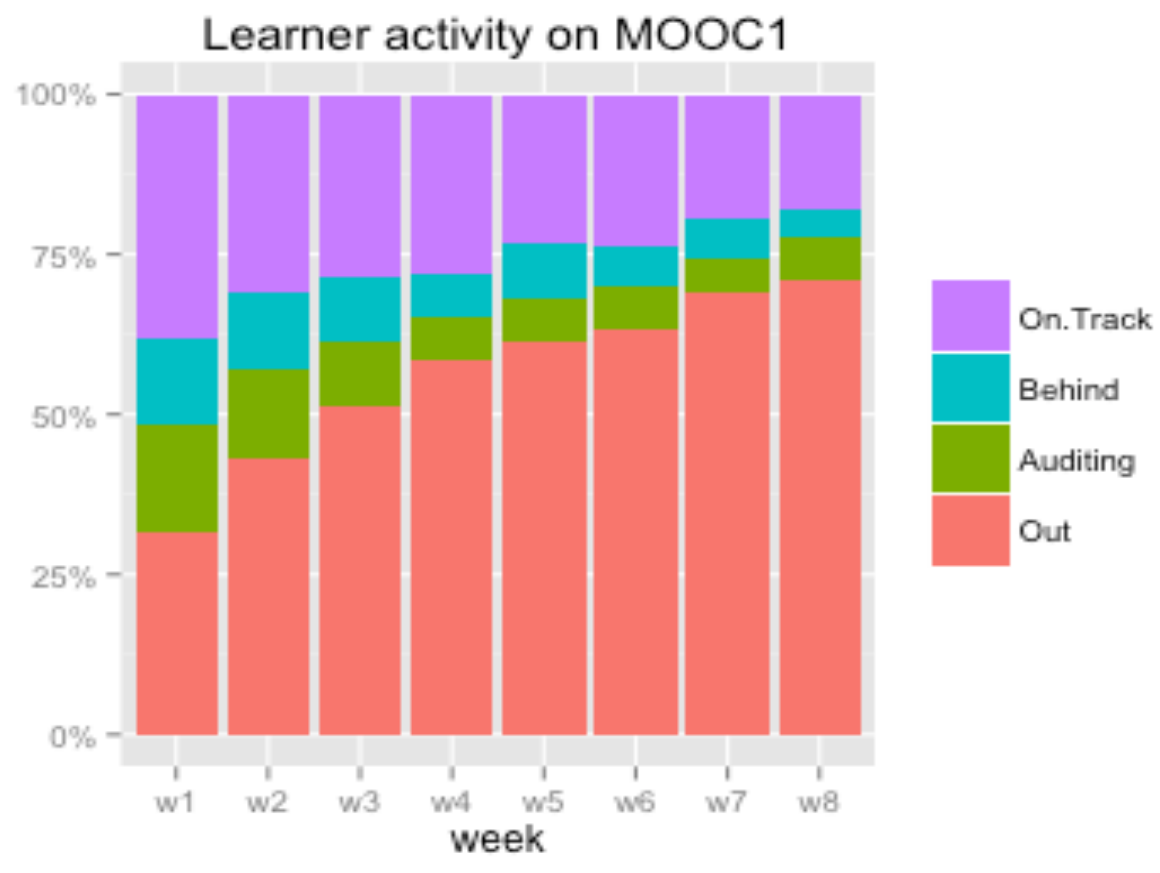

Figure 2: Proportion of users on Study One MOOC1 falling into each category, by week

We also followed their practice in repeating clustering 100 times and selecting the solution with the highest likelihood, because $k$-means has random aspects.

To attempt to replicate their findings, we focused on extracting four clusters. However, our clusters did not match those found in the Coursera study. The method produced two clusters that were very similar to the ones they found. We found a cluster strikingly similar to their "Completing" group: learners who completed almost all the assessments. We also found a cluster similar to their "Sampling" group: learners who visited only once or twice, and did not attempt any assessment. 
(2015). Consistent commitment: Patterns of engagement across time in Massive Open Online Courses (MOOCs). Journal of Learning Analytics, 2(3), 55-80. http://dx.doi.org/10.18608/jla.2015.23.5

The other two clusters did not match theirs so well. They found an "Auditing" cluster "who did assessments infrequently if at all and engaged instead by watching video lectures," and a "Disengaging" cluster "who did assessments at the beginning of the course but then have a marked decrease in engagement." Our two equivalent clusters did include some learners with patterns like that, but they also included many who did not fit those descriptions neatly, and there seemed to be significant overlap. This was reflected in the silhouette scores: they reported an average silhouette width of 0.8 , but our data achieved only 0.67 . (The closer to 1.0 , the better clustered.)

Selecting a number of clusters, $k$, to extract using $k$-means is notoriously problematic, unless there is an unambiguous a priori rationale. A notable feature of $k$-means clustering is that it will always generate $k$ clusters regardless of whether another number would provide a better fit for the data.

We therefore repeated the analysis using values for $k$ that ranged from 3 to 8 . We found that the silhouette width was at a minimum for $k=4$, suggesting that this might be the least suitable number of clusters for our data.

We were concerned that the one-dimensional approach was discarding potentially useful information about patterns of engagement before the clustering algorithm could use them, so we repeated the analysis again, this time running $k$-means on the numeric engagement profiles directly, treating them as six- or eight-dimensional vectors. We explored the four-cluster solution in detail, and again found "Completing" and "Sampling" clusters, but no clear pattern in the other two.

Again, we explored $k$ from 3 to 8 , which yielded silhouette widths rather lower than for the onedimensional approach (around 0.4 ), and which decreased monotonically as $k$ increased.

\subsection{Adapting the Method}

Having had mixed results from direct application of the method, we planned to adapt their method, making a minimal number of changes to reflect the context of our data.

We developed a new classification, in order to reflect the importance of discussion in FutureLearn MOOCs. For each content week, students were assigned the value 1 if they viewed content, 2 if they posted a comment, 4 if they submitted the week's assessment late and 8 if they completed the final assessment before the end of the week in which it was set (i.e., early, or on time). These values were added up to give a total for each week. The possible scores that could be assigned to an individual learner in any one week are set out in Table 2 (below).

The majority of comments on FutureLearn are associated with a content step, as study weeks typically include only one or two discussion steps. There is therefore no way to tell from our log data whether 
(2015). Consistent commitment: Patterns of engagement across time in Massive Open Online Courses (MOOCs). Journal of Learning Analytics, 2(3), 55-80. http://dx.doi.org/10.18608/jla.2015.23.5

learners had participated in the discussion by reading but not by adding a comment, so this option could not be coded.

Table 2: Scoring method

\begin{tabular}{cl}
\hline Score & Interpretation \\
\hline 1 & only visited content (for example, video, audio, text) \\
2 & commented but visited no new content \\
3 & visited content and commented \\
4 & did the assessment late and did nothing else that week \\
5 & visited content and did the assessment late \\
6 & did the assessment late, commented, but visited no new content \\
7 & visited content, commented, late assessment \\
8 & assessment early or on time, but nothing else that week \\
9 & visited content and completed assessment early/on time \\
10 & assessment early or on time, commented, but visited no new content \\
\hline
\end{tabular}

We used the $k$-means algorithm to extract clusters from the engagement profiles directly, as a six- or eight-dimensional vector for each learner, to allow for the possibility of clustering by time of activity, as well as by total activity. The variation in dimensions here was because three of these MOOCs ran for eight weeks but MOOC2, the life sciences MOOC, ran for six weeks.
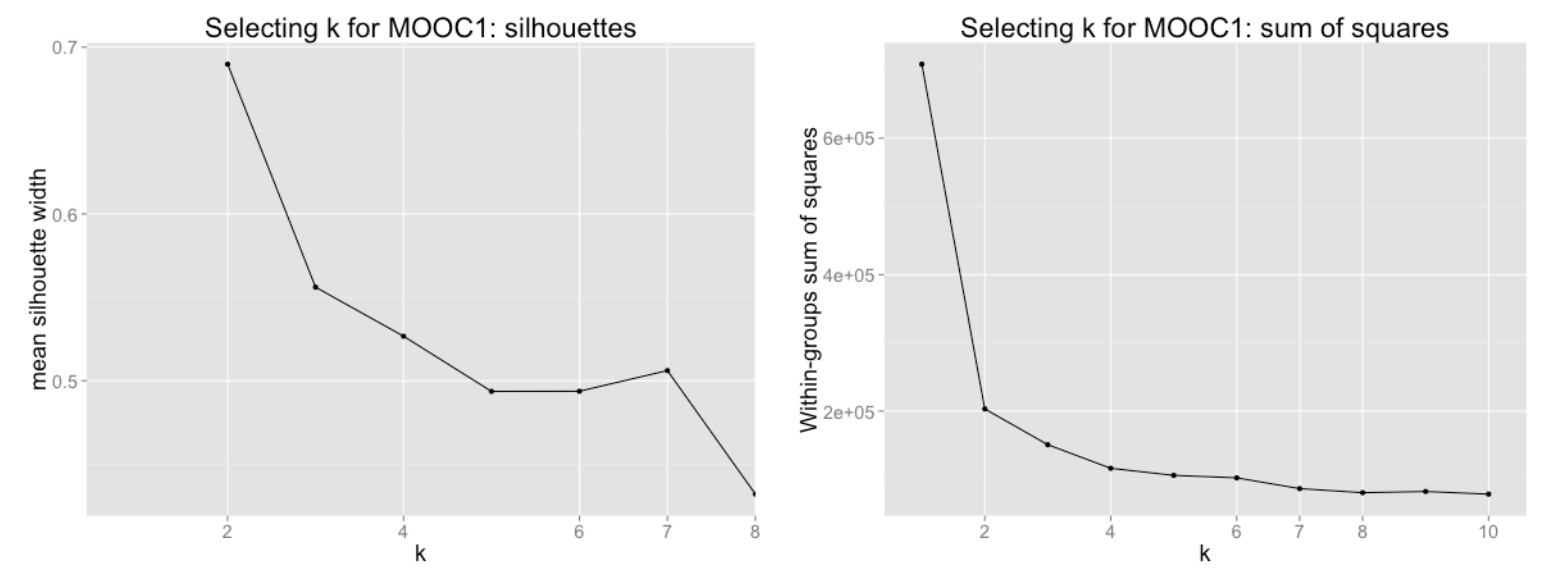

Figure 3: Study One silhouette widths for $k=2$ to 8 (left) and scree plot of the within-groups sum of squares for $k=1$ to 10 (right)

Selecting a number of clusters to extract was very problematic. A wide variety of techniques was employed, almost all of which yielded unhelpful results, recommending either a minimal number of clusters (2) or a maximal number. ${ }^{2}$

\footnotetext{
${ }^{2}$ Specifically, we applied all the techniques listed in this Stack Exchange post: http://stackoverflow.com/questions/15376075/cluster-analysis-in-r-determine-the-optimal-number-ofclusters/15376462
} 
(2015). Consistent commitment: Patterns of engagement across time in Massive Open Online Courses (MOOCs). Journal of Learning Analytics, 2(3), 55-80. http://dx.doi.org/10.18608/jla.2015.23.5

This in itself suggests that this entire approach to clustering was far from ideal. However, we wished to pursue the approach to explore whether the clusters nonetheless had the vivid face validity of the Kizilcec et al. paper. Manual inspection of the two-cluster solution suggested that this separated the learners into those who visited only briefly (Samplers - see below) and others. We wished to explore the other patterns of engagement in some detail. A maximal number of clusters would be uninformative and unwieldy analytically.

Two methods supported a pragmatic decision to extract seven clusters. The mean silhouette width reached a local maximum at $k=7$ (see Figure 3 , left). We also used a scree plot to visualize the total withingroups sum of squares (the measure of how closely the clusters group together that $k$-means seeks to minimize). The method in using a scree plot is to identify a "kink" in the plot, which is somewhat subjective. In this case, the within-groups sum of squares dipped at $k=7$ (see Figure 3 , right).

\subsection{Analysis of Clusters}

Our cluster descriptions were developed by analysis of learner profiles on MOOC1. Like Kizilcec and colleagues, we wanted to ensure that the clusters made sense from an educational point of view, even though these descriptions were developed after the analysis had taken place. After developing the cluster profiles for MOOC1, we examined the other Study One MOOCs. With three exceptions, there was very close agreement between the clusters found.

Two of the MOOCs were structurally different to the others. MOOC1, MOOC3, and MOOC4 ran for eight weeks, but MOOC2 ran for only six weeks. MOOC1, MOOC2, and MOOC4 included assessment every week, but MOOC3 included only three assessments.

Despite these differences, five of the seven clusters were found in substantially identical form in all four MOOCs. MOOC2 and MOOC3 between them generated three clusters that did not match those developed on MOOC1, which are appended to the list as supplementary clusters.

Cluster descriptions for Study One are given below, together with notes of where individual MOOCs differed. The clusters found across all four MOOCs are indicated with a ${ }^{*}$, as well as in the text. The proportion of learners in each cluster is shown in Table 3 (below). In all cases, the term "average" refers to the mean. We have provided typical engagement profiles for each cluster, which we derived by inspecting the profiles within each cluster manually, and selecting one that occurred very frequently.

\section{Cluster I: Samplers*}

Learners in this cluster visited, but only briefly. This cluster is essentially identical to Kizilcec et al.'s "Sampling" cluster. Samplers made up the largest cluster in all four MOOCs, accounting for 37\%-39\% of learners (56\% on MOOC4). They typically visited about $5 \%$ of the course, with a few Samplers (11\%-24\%) visiting only a single step, although only $1 \%$ of Samplers on MOOC3 did so. They were active in a very small 
(2015). Consistent commitment: Patterns of engagement across time in Massive Open Online Courses (MOOCs). Journal of Learning Analytics, 2(3), 55-80. http://dx.doi.org/10.18608/jla.2015.23.5

number of weeks, often including week 1 , but not always - $25 \%-40 \%$ joined the course after the first week. Very few Samplers posted comments (6\%-15\%), and very few submitted any assessment, although the handful that did so typically did this in week 1.

A typical engagement profile for this cluster shows individuals looking at content in Week 1 and not engaging in subsequent weeks: $[1,0,0,0,0,0,0,0]$. This cluster was highly stable across all MOOCs, and across most values of $k$.

\section{Cluster II: Strong Starters*}

These learners completed the first assessment of the course, but then dropped out.

Strong Starters made up $8 \%-14 \%$ of learners. All of them submitted the first assignment, but then their engagement dropped off sharply, with very little activity after that. A little over a third of them posted comments (35\%-38\%), and those who did so did not post very many (1.7-4.0), except on MOOC3, where $73 \%$ of learners posted an average of 13.7 comments.

A typical engagement profile for this cluster shows them visiting content and submitting their assessment on time in Week 1 , visiting content in Week 2 , then disengaging: $[9,1,0,0,0,0,0,0]$. Again, this cluster was highly stable across all MOOCs and most values of $k$.

\section{Cluster III: Returners}

These learners completed the assessment in the first week, returned to do so again in the second week, and then dropped out.

Returners made up $6 \%-8 \%$ of learners, with the exception of those studying MOOC3, where this cluster did not appear. This was almost certainly because there were only three assessments in that course, with at least one week between each, so this pattern of activity was not possible. Almost all the learners in this cluster $(>97 \%)$ submitted the assessments for week 1 and week 2 . This does not mean that they all visited in both weeks; some of them did the week 1 assessment late. No Returners explored all the course steps; the average amount of steps visited varied from $23 \%$ to $47 \%$. After the first two weeks, there was very little activity indeed.

A typical engagement profile for this cluster shows individuals viewing content and completing assessments on time in the first two weeks, but then disengaging: $[9,9,0,0,0,0,0,0]$. This cluster showed some variability with varying $k$.

\section{Cluster IV: Mid-way Dropouts}

These learners completed three or four assessments, but dropped out about half-way through the course. 
(2015). Consistent commitment: Patterns of engagement across time in Massive Open Online Courses (MOOCs). Journal of Learning Analytics, 2(3), 55-80. http://dx.doi.org/10.18608/jla.2015.23.5

Mid-way Dropouts made up 6\% of learners on MOOC1, and 7\% of learners on MOOC4. This cluster did not appear for $\mathrm{MOOC2}$ and $\mathrm{MOOC3}$, because their unusual structure (shorter, fewer assessments) meant that there were not enough assessments other than the final one for them to have this profile. These learners visited about half of the course $(47 \%, 59 \%)$, and roughly half of them posted comments (38\%, $49 \%)$, posting $6.3-6.5$ comments on average.

A typical engagement profile for this cluster shows individuals submitting assessments on time in the first three weeks, submitting late in the fourth week, viewing content in weeks five and six and then dropping out: $[9,9,9,4,1,1,0,0]$. This cluster, like the previous one, showed some variability with varying $k$.

\section{Cluster V: Nearly There*}

These learners consistently completed assessments, but then dropped out just before the end of the course.

Nearly There learners accounted for $5 \%-6 \%$ of learners on all four MOOCs. They typically visited over three-quarters of the course $(72 \%-80 \%)$ and submitted assessments consistently (>90\%) until week 5 , and mostly on time $(40 \%-75 \%)$, after which their activity declined steeply, and few completed the final assessment (3\%-17\%), none on time. Many of them posted comments (48\%-65\%), and those who did posted an average of 5.7-8.3 - except for MOOC3, where $80 \%$ of learners posted an average of 21.8 comments each.

A typical engagement profile for this cluster shows high engagement early on, viewing content and submitting on time in the first six weeks, and sometimes commenting as well, then submitting the assessment in week seven and ceasing to engage: $[11,11,9,11,9,9,8,0]$. This cluster appeared definitively for all four MOOCs, but was somewhat variable with varying $k$.

\section{Cluster VI: Late Completers*}

This cluster includes learners who completed the final assessment, and submitted most of the other assessments, but were either late or omitted some.

Late Completers accounted for $6 \%-8 \%$ of learners, except on MOOC3, where only $0.2 \%$ of learners fell into this cluster. This was presumably because MOOC3 only included three assessment points, so there were fewer opportunities to get behind on the assessment. Each week, including the final week, more than $94 \%$ of this cluster submitted their assessment. The average proportion submitting late varied from $16 \%$ to $59 \%$. However, more than three-quarters submitted the final assessment on time (78\%-90\%). Fewer than half of these learners posted comments (40\%-43\%), apart from on MOOC3 where $76 \%$ did so, and those that posted made an average of 7.9-15.0 comments. 
(2015). Consistent commitment: Patterns of engagement across time in Massive Open Online Courses (MOOCs). Journal of Learning Analytics, 2(3), 55-80. http://dx.doi.org/10.18608/jla.2015.23.5

A typical engagement profile for this cluster shows individuals visiting content and submitting assessments late in the first five weeks, and then viewing content and submitting assessments on time in the final week: $[5,5,5,5,5,9,9,9]$. This cluster was fairly stable across all MOOCs, and across most values of $k$.

Cluster VII: Keen Completers*

This cluster consists of learners who completed the course diligently, engaging actively throughout.

Keen Completers accounted for $7 \%$ to $13 \%$ of learners, apart from on MOOC1, where $23 \%$ of learners fell into this cluster. All learners in this cluster completed all the assessments, including the final one, and almost all of them on time ( $>80 \%$ ). On average, the Keen Completers visited $>90 \%$ of the course content. They were also assiduous commenters. About two-thirds of this cluster (68\%-73\%) contributed $20.8-24.4$ comments on average, although again MOOC3 stood out, with all learners commenting, posting an impressive average of 53.7 comments each.

A typical engagement profile for this cluster shows individuals viewing comment and submitting assessment on time every week, and also commenting in several weeks: $[11,11,9,9,11,11,9$, 9]. This cluster was highly stable across all MOOCs, and across values of $k$.

\section{MOOC2 Supplementary Cluster}

Because it was shorter than the other MOOCs, the Mid-way Dropouts cluster was not found on this MOOC. Instead, a rather miscellaneous and hard-to-interpret cluster was generated, falling between Samplers and Strong Starters, and accounting for $13 \%$ of the learners. Sixty-seven percent of the cluster submitted the first assessment, but late, and many either visited regularly or left comments.

\section{MOOC3 Supplementary Cluster 1}

MOOC3 had only three assessments, so the Returners and Mid-way Dropouts clusters were not found. The first alternative cluster was a substantial one, accounting for $20 \%$ of learners. It was very similar to the Samplers cluster in that the learners visited only briefly - however, all of them left comments. They left an average of 5.3 comments, which is high compared to the other MOOCs, but low for MOOC3.

\section{MOOC3 Supplementary Cluster 2}

The second alternative cluster was much smaller, accounting for only $2 \%$ of MOOC3. These learners submitted the final assessment on time, but did not engage consistently across the course. In this cluster, $44 \%$ submitted the first assessment, $22 \%$ the second. They visited on average $44 \%$ of the course. About half of these learners left comments (53\%), at a rate of 10.1 each. 
(2015). Consistent commitment: Patterns of engagement across time in Massive Open Online Courses (MOOCs). Journal of Learning Analytics, 2(3), 55-80. http://dx.doi.org/10.18608/jla.2015.23.5

Table 3: Proportion of learners in each Study One cluster, by MOOC

\begin{tabular}{l|rrrr}
\hline Cluster & MOOC1 & MOOC2 & MOOC3 & MOOC4 \\
\hline I Samplers & $39 \%$ & $39 \%$ & $37 \%$ & $56 \%$ \\
II Strong Starters & $11 \%$ & $14 \%$ & $8 \%$ & $10 \%$ \\
III Returners & $6 \%$ & $8 \%$ & - & $7 \%$ \\
IV Mid-way Dropouts & $6 \%$ & - & - & $7 \%$ \\
V Nearly There & $6 \%$ & $6 \%$ & $6 \%$ & $5 \%$ \\
VI Late Completers & $8 \%$ & $7 \%$ & $0.2 \%$ & $6 \%$ \\
VII Keen Completers & $23 \%$ & $13 \%$ & $7 \%$ & $9 \%$ \\
MOOC2 Sup & - & $13 \%$ & - & - \\
MOOC3 Sup 1 & - & - & $20 \%$ & - \\
MOOC3 Sup 2 & - & - & $2 \%$ & - \\
\hline
\end{tabular}

\section{$4 \quad$ DISCUSSION OF STUDY ONE}

Kizilcec and colleagues found four clusters within their data: learners who were completing, auditing, disengaging, and sampling (Kizilcec, Piech, \& Schneider, 2013). They identified these clusters after structuring their data in a way that placed emphasis on learner interaction with content, assessment, and deadlines. As Section 3.1 showed, we found "Completing" and "Sampling" clusters, but the others were not found so clearly within the FutureLearn datasets.

The socio-constructivist pedagogy of FutureLearn incorporates not only content and assessment within a course's learning design but also discussion. In addition, as credit is not currently available for FutureLearn courses, assessment is typically used formatively (to support learning) rather than summatively (to gauge how much has been learned). The results of our analysis differed from Kizilcec et al., which suggests that this different context may have influenced the results. Our approach included data about contribution to discussion as an input, and some of the clusters we found reflected particular patterns of participation in discussion. This suggests that a single approach is unlikely to be pedagogy-neutral. We suggest that opportunities for joint knowledge construction should be taken into account where they are available.

The "Sampling" cluster identified in 2013 (Kizilcec, Piech, \& Schneider, 2013) can be related to two clusters in the current study: the Samplers and the Strong Starters. The Samplers cluster includes people who arrived, visited a few pieces of content, and then left. However, it also includes many learners who arrived late - in Week 1, in Week 2 or even later in the course, and who then did not sustain their engagement. In many cases, this late arrival may have indicated that they never intended to engage with the entire course. However, it is likely that many found and joined the course after its start, or were unable to take part in its early days. This suggests that the time-bounded nature of the course, with a cohort working through the material together week by week, may have discouraged participation by late arrivals.

The Strong Starters appear, in the FutureLearn datasets, to be distinct from the Samplers. On average, they completed the first week, they made one or two comments, and many of them looked beyond the 
(2015). Consistent commitment: Patterns of engagement across time in Massive Open Online Courses (MOOCs). Journal of Learning Analytics, 2(3), 55-80. http://dx.doi.org/10.18608/jla.2015.23.5

first week's materials. These learners did more than simply sample content, but were not able to sustain their engagement with the course.

The clusters of Strong Starters, Returners, Mid-way Dropouts, and Nearly There are chiefly distinguished by the time period over which their members engaged with the course. Strong Starters engaged for a week, Returners for a couple of weeks, Mid-way Dropouts for about half the course, and Nearly There for all but the last week or two. Not surprisingly, an increase in time spent on the course was associated with a rise in the mean proportion of the course visited by group members and a rise in the mean number of comments contributed.

The two clusters of Late Completers and Keen Completers can be considered as a pair, because they include the learners who have engaged with the majority of the material and all the assessments and who are therefore classified by FutureLearn as Fully Participating learners. The main characteristic that differentiates the two clusters is the number of comments posted. All the clusters considered previously in the analysis averaged about one post per person per week of engagement. On average, Samplers engaged for less than a week and posted less than one comment. Strong Starters participated for just over a week and posted just over one comment. Returners participated for a little over two weeks and posted just over two comments. Learners in the Nearly There cluster engaged for four to six weeks and posted around five comments. The Late Completers cluster also broadly followed this one-comment-per-week average. However, the Keen Completers posted twice as much as those clusters, averaging well over two comments per week.

It seems, then, that there were two dominant approaches to completing the course. The more popular approach (there were consistently more Keen Completers than Late Completers) was to engage fully. Keen Completers did almost everything, every week, and visited almost every step of the course. The Late Completers group did not engage with every aspect of the course: they commented less, and they were more frequently late in submitted assessments. So engaging actively with the comments is associated with a more extensive engagement with the course materials and assessment than is apparent in other clusters.

\subsection{Exploring the Clusters in More Detail}

A subsequent study, reported at EC-TEL 2015 (Ferguson et al., 2015), explored these clusters in more detail, examining learner engagement with MOOCs run by different universities on the FutureLearn platform. That study found that the seven main clusters identified in this paper were consistently found on seven- to eight-week MOOCs that support engagement with content, assessment, and discussion.

These studies showed that the process of developing a "simple and scalable categorization to target interventions" (Kizilcec, Piech, \& Schneider, 2013) is not as straightforward as it originally seemed. Studies of engagement suggest, perhaps unsurprisingly, that all MOOCs include learners who arrive, look around 
a little, and then leave, as well as learners who arrive, engage with everything, and stay until the end. However, a large percentage of learners ( $37 \%$ in MOOC1, for example) do not fit these patterns. How these learners behave depends on the pedagogy of the course, and on how it is designed. A variation in course length, as with MOOC2, introduces new clusters, as does a variation in assessment patterns, as was the case with MOOC3.

If engagement patterns shift with pedagogy and learning design, do they also shift as educators become more experienced and learners grow more familiar with learning in MOOCs? To answer this question, we returned to MOOC1 and MOOC4 - the eight-week MOOCs with assessment points each week - and studied both the first and the second presentation of each of these courses.

\section{$5 \quad$ STUDY TWO: IDENTIFYING PATTERNS OF ENGAGEMENT ACROSS TIME}

\subsection{Study Two: Dataset}

Table 4 (below) provides a brief overview of the dataset for Study 2, the two presentations of MOOC1 and MOOC4. This overview supplements, and to some extent repeats, the information provided about these two MOOCs in Table 1 above. The figures for gender and for previous experience of online courses and MOOCs are taken from responses to the start-of-course survey for each presentation. The number of participants indicates the number of individuals - both educators and learners - who appeared in our dataset because they were active after the start date of the course. People who were active before the start date were removed from the dataset entirely, because the only people with access at that point were educators or FutureLearn staff. Fully Participating learners marked a majority of the course steps complete and completed all the assessments.

Although the two presentations of each course were run less than a year apart, there is a change in participants' reported previous experience. In both cases, experience of courses run partly or solely online rises by two percentage points (n.s. for either). At the same time, previous experience of MOOCs rises by six to eight percentage points ( $p<0.01$ for MOOC1, $p<0.001$ for MOOC2). This implies that the second presentation of MOOC4 had around 780 more participants with experience of MOOCs than it did on its first presentation, while the second presentation of MOOC4 had around 1,380 more participants with experience of MOOCs than it did on its first presentation.

\subsection{Study Two: Method}

For Study Two, we followed the method outlined in Section 3.2 (above). Individuals' engagement each week was scored using the values set out in Table 2 (above). Values assigned for different types of activity were totalled to assign each individual an engagement score ranging from 0 to 11 each week. The engagement scores for each of the eight weeks of the course were used to produce an engagement profile 
containing eight values for each learner. The $k$-means algorithm was used as before to extract seven clusters from these engagement profiles as an eight-dimensional vector for each learner.

Table 4: Overview of dataset for Study Two

\begin{tabular}{l|rr|rr}
\hline & $\begin{array}{c}\text { MOOC1 } \\
\text { first }\end{array}$ & $\begin{array}{c}\text { MOOC1 } \\
\text { second }\end{array}$ & $\begin{array}{c}\text { MOOC4 } \\
\text { first }\end{array}$ & $\begin{array}{c}\text { MOOC4 } \\
\text { second }\end{array}$ \\
\hline Subject area & $\begin{array}{l}\text { Physical } \\
\text { Sciences }\end{array}$ & $\begin{array}{c}\text { Physical } \\
\text { Sciences }\end{array}$ & Business & Business \\
Start month & Mar 2014 & Feb 2015 & May 2014 & Mar 2015 \\
\hline M & $51 \%$ & $50 \%$ & $35 \%$ & $36 \%$ \\
F & $48 \%$ & $50 \%$ & $65 \%$ & $64 \%$ \\
Taken online course before & $65 \%$ & $67 \%$ & $55 \%$ & $57 \%$ \\
Taken MOOC before & $48 \%$ & $54 \%$ & $32 \%$ & $40 \%$ \\
Participants & 5,069 & 5,953 & 9,778 & 11,264 \\
\hline Fully Participating & 1,548 & 1,304 & 1,416 & 1,240 \\
Participation Rate & $31 \%$ & $30 \%$ & $14 \%$ & $11 \%$ \\
\hline
\end{tabular}

\subsection{Study Two: Analysis of Clusters}

The seven clusters for the second presentation of MOOC1 and MOOC4 were found on manual inspection to align very closely with those identified in Study One. Quantifying this similarity in the absence of an independent output variable is far from straightforward. As a simplistic but hopefully comprehensible approach, we calculated a series of descriptive statistics to facilitate comparison.

Size: What percentage of learners was included in the cluster? Was any cluster consistently larger or smaller than the others?

Steps: Each FutureLearn MOOC is divided into steps. A mean number of steps visited for each cluster was calculated by totalling all step visits and dividing by the number of learners in the cluster. This mean number was then compared with the total number of steps in the MOOC.

Comments: What percentage of learners in the cluster added at least one comment to the MOOC discussion?

Assessment: What percentage of learners in the cluster ever completed the first assessment? How many assignments were completed by at least $90 \%$ of the cluster?

Considering these four areas enabled a detailed comparison of the attributes of each cluster.

\subsubsection{Study Two: Samplers}

Samplers (Table 5), the least engaged learners, make up the biggest cluster in each presentation of these two MOOCs. On average, they very consistently visited $4-5 \%$ of the steps. However, more than a fifth of 
(2015). Consistent commitment: Patterns of engagement across time in Massive Open Online Courses (MOOCs). Journal of Learning Analytics, 2(3), 55-80. http://dx.doi.org/10.18608/jla.2015.23.5

them visited only one step and left after their first visit. This cluster also contains a very high percentage of latecomers, with more than a third first visiting the course after its first week. Relatively few commented and few did the first - or any - assessment.

Table 5: Study Two - Samplers

\begin{tabular}{l|r|r|r|r|r}
\hline & MOOC1 1st & MOOC1 2nd & MOOC4 1st & MOOC4 2nd & $\begin{array}{r}\text { Cluster } \\
\text { characteristics }\end{array}$ \\
\hline Size of cluster & $39 \%$ & ${ }^{* * *} 47 \%$ & $56 \%$ & $56 \%$ & Over a third \\
\hline Mean \% steps visited & $5 \%$ & $5 \%$ & $5 \%$ & $4 \%$ & $5 \%-10 \%$ \\
\hline \% Visit only one step & $24 \%$ & ${ }^{* * *} 32 \%$ & $24 \%$ & ${ }^{* * *} 27 \%$ & $>20 \%$ \\
\hline \% Join after week 1 & $27 \%$ & ${ }^{* * *} 34 \%$ & $39 \%$ & ${ }^{* * *} 35 \%$ & $>25 \%$ \\
\hline \% Leave a comment & $15 \%$ & ${ }^{* * *} 11 \%$ & $13 \%$ & $12 \%$ & $<20 \%$ \\
\hline \% Do first assessment & $4 \%$ & $5 \%$ & $13 \%$ & ${ }^{* * *} 7 \%$ & $=<15 \%$ \\
\hline \% Do any assessment & $6 \%$ & $6 \%$ & $15 \%$ & ${ }^{* * *} 10 \%$ & $=<15 \%$ \\
\hline
\end{tabular}

${ }^{*} p<0.05,{ }^{* *} p<0.01, * * * p<0.001$ between $1^{\text {st }}$ and $2^{\text {nd }}$

\subsubsection{Study Two: Strong Starters}

The Strong Starters (Table 6) are a smaller cluster than the Samplers (Table 5), but they are much more engaged. They visit more steps, a lot of them comment, and all of them complete the first assessment. However, few of them go on to do more assessments.

Table 6: Study Two - Strong Starters

\begin{tabular}{l|r|r|r|r|r}
\hline & MOOC1 1st & MOOC1 2nd & MOOC4 1st & MOOC4 2nd & $\begin{array}{r}\text { Cluster } \\
\text { characteristics }\end{array}$ \\
\hline Size of cluster & $11 \%$ & $12 \%$ & $10 \%$ & ${ }^{* *} 14 \%$ & $8 \%-14 \%$ \\
\hline Mean \% steps visited & $17 \%$ & $17 \%$ & $12 \%$ & $11 \%$ & $10 \%-20 \%$ \\
\hline \% Visit only one step & $37 \%$ & ${ }^{* * *} 27 \%$ & $35 \%$ & ${ }^{* * *} 28 \%$ & $20 \%-40 \%$ \\
\hline \% Do first assessment & $100 \%$ & $100 \%$ & $100 \%$ & $100 \%$ & $100 \%$ \\
\hline$\%$ Do $>1$ assessment & $5 \%$ & $6 \%$ & $7 \%$ & ${ }^{*} 5 \%$ & $<10 \%$ \\
\hline
\end{tabular}

$* p<0.05, * * p<0.01,{ }^{* * *} p<0.001$ between $1^{\text {st }}$ and $2^{\text {nd }}$

\subsubsection{Study Two: Returners}

The Returners (Table 7) make up a small, but fairly active cluster. They engage with a lot of the content, although none of them looks at it all. Most of them do the first assessment and go on to do another assessment, and a lot of them engage by commenting. 
(2015). Consistent commitment: Patterns of engagement across time in Massive Open Online Courses (MOOCs). Journal of Learning Analytics, 2(3), 55-80. http://dx.doi.org/10.18608/jla.2015.23.5

Table 7: Study Two - Returners

\begin{tabular}{l|r|r|r|r|r}
\hline & \multicolumn{1}{|l|}{$\begin{array}{l}\text { MOOC1 } \\
\text { 1st }\end{array}$} & $\begin{array}{l}\text { MOOC1 } \\
\text { 2nd }\end{array}$ & $\begin{array}{l}\text { MOOC4 } \\
\text { 1st }\end{array}$ & $\begin{array}{l}\text { MOOC4 } \\
\text { 2nd }\end{array}$ & $\begin{array}{l}\text { Cluster } \\
\text { characteristics }\end{array}$ \\
\hline Size of cluster & $6 \%$ & $8 \%$ & $7 \%$ & $8 \%$ & $6 \%-8 \%$ \\
\hline Mean \% steps visited & $33 \%$ & $36 \%$ & $24 \%$ & $26 \%$ & $20 \%-50 \%$ \\
\hline \% Visit all steps & $0 \%$ & $0 \%$ & $0 \%$ & $0 \%$ & $0 \%$ \\
\hline$\%$ Leave a comment & $39 \%$ & $35 \%$ & $23 \%$ & ${ }^{* * *} 32 \%$ & $>20 \%-60 \%$ \\
\hline \% Do first assessment & $95 \%$ & $96 \%$ & $93 \%$ & $94 \%$ & $>90 \%$ \\
\hline$\%$ Do $>1$ assessment & $95 \%$ & $96 \%$ & $91 \%$ & $91 \%$ & $>90 \%$ \\
\hline
\end{tabular}

*** $p<0.001$ between $1^{\text {st }}$ and $2^{\text {nd }}$

\subsubsection{Study Two: Midway Dropouts}

The Midway Dropouts (Table 8) make up another small cluster. Almost all of them do the first assessment, and most do three or more assessments. About half of them comment at least once, and they view about half of the course content.

Table 8: Study Two - Midway Dropouts

\begin{tabular}{l|r|r|r|r|r}
\hline & MOOC1 1st & MOOC1 2nd & MOOC4 1st & MOOC4 2nd & $\begin{array}{r}\text { Cluster } \\
\text { Characteristics }\end{array}$ \\
\hline Size of cluster & $6 \%$ & $7 \%$ & $7 \%$ & $6 \%$ & $6 \%-7 \%$ \\
\hline Mean \% steps visited & $59 \%$ & $65 \%$ & $49 \%$ & $48 \%$ & $45 \%-65 \%$ \\
\hline$\%$ Leave a comment & $49 \%$ & $43 \%$ & $38 \%$ & ${ }^{* *} 46 \%$ & $35 \%-50 \%$ \\
\hline \% Do first assessment & $98 \%$ & $97 \%$ & $96 \%$ & ${ }^{* * *} 99 \%$ & $>95 \%$ \\
\hline$\%$ Do $>2$ assessments & $97 \%$ & $99 \%$ & $96 \%$ & ${ }^{*} 98 \%$ & $>90 \%$ \\
\hline
\end{tabular}

$* p<0.05, * * p<0.01, * * * p<0.001$ between $1^{\text {st }}$ and $2^{\text {nd }}$

\subsubsection{Study Two: Nearly There}

Nearly There (Table 9) is consistently the smallest cluster, made up of people who view most of the course content and do most of the assessment. They are also more likely than not to post a comment.

Table 9: Study Two - Nearly there

\begin{tabular}{l|r|r|r|r|r}
\hline & MOOC1 1st & MOOC1 2nd & MOOC4 1st & MOOC4 2nd & $\begin{array}{r}\text { Cluster } \\
\text { Characteristics }\end{array}$ \\
\hline Size of cluster & $6 \%$ & $5 \%$ & $5 \%$ & $4 \%$ & $4 \%-6 \%$ \\
\hline Mean \% Steps visited & $76 \%$ & ${ }^{* * *} 89 \%$ & $76 \%$ & $74 \%$ & $70 \%-90 \%$ \\
\hline \% Leave a comment & $65 \%$ & $53 \%$ & $48 \%$ & ${ }^{* *} 55 \%$ & $45 \%-65 \%$ \\
\hline$\%$ Do first assessment & $98 \%$ & $98 \%$ & $99 \%$ & $99 \%$ & $>95 \%$ \\
\hline$\%$ Do $>4$ assessments & $99 \%$ & ${ }^{* * *} 100 \%$ & $97 \%$ & $97 \%$ & $>90 \%$ \\
\hline
\end{tabular}

\subsubsection{Study Two: Late Completers}

In most cases, the engagement in clusters rises consistently. Each cluster described above has viewed more content than the last, included more people who comment than the last, and completed more assessments than the last. The Late Completers (Table 10) are an exception. They visit almost all the steps, they do almost all of the assessment, but the percentage that comment is relatively low. 
(2015). Consistent commitment: Patterns of engagement across time in Massive Open Online Courses (MOOCs). Journal of Learning Analytics, 2(3), 55-80. http://dx.doi.org/10.18608/jla.2015.23.5

Table 10: Study Two - Late completers

\begin{tabular}{l|r|r|r|r|r}
\hline & MOOC1 1st & MOOC1 2nd & MOOC4 1st & Mooc4 2nd & $\begin{array}{r}\text { Cluster } \\
\text { Characteristics }\end{array}$ \\
\hline Size of cluster & $8 \%$ & $6 \%$ & $6 \%$ & $4 \%$ & $6 \%-8 \%$ \\
\hline Mean \% steps visited & $92 \%$ & $95 \%$ & $95 \%$ & $92 \%$ & $90 \%-97 \%$ \\
\hline$\%$ Leave a comment & $44 \%$ & $38 \%$ & $42 \%$ & ${ }^{*} 36 \%$ & $35 \%-45 \%$ \\
\hline$\%$ Do first assessment & $96 \%$ & $97 \%$ & $98 \%$ & $97 \%$ & $>95 \%$ \\
\hline$\%$ Do $>6$ assessments & $93 \%$ & $93 \%$ & $95 \%$ & ${ }^{* * *} 89 \%$ & $>90 \%$ \\
\hline
\end{tabular}

$* p<0.05,{ }^{* *} p<0.01, * * * p<0.001$ between $1^{\text {st }}$ and $2^{\text {nd }}$

\subsubsection{Study Two: Keen Completers}

The Keen Completers (Table 11) can be considered ideal MOOC students from an educator's perspective. They visit all, or almost all, of the content. They do all, or almost all of the assessment. Two-thirds of them add to the course by commenting. They represent most, but not all, of the learners classified as "Fully Participating" and therefore eligible for a FutureLearn Statement of Participation.

Table 11: Study Two - Keen completers

\begin{tabular}{l|r|r|r|r|r}
\hline & MOOC1 1st & MOOC1 2nd & MOOC4 1st & MOOC4 2nd & $\begin{array}{r}\text { Cluster } \\
\text { characteristics }\end{array}$ \\
\hline Size of cluster & $23 \%$ & ${ }^{* * *} 15 \%$ & $9 \%$ & $8 \%$ & $8 \%-23 \%$ \\
\hline Mean \% steps visited & $95 \%$ & $100 \%$ & $98 \%$ & $99 \%$ & $95 \%-100 \%$ \\
\hline \% Leave a comment & $71 \%$ & $66 \%$ & $68 \%$ & $67 \%$ & $65 \%-75 \%$ \\
\hline \% Do first assessment & $100 \%$ & $100 \%$ & $100 \%$ & $100 \%$ & $>98 \%$ \\
\hline \% Do $>7$ assessments & $99 \%$ & $99 \%$ & $100 \%$ & $100 \%$ & $>90 \%$ \\
\hline
\end{tabular}

$* p<0.05, * * p<0.01, * * * p<0.001$ between $1^{\text {st }}$ and $2^{\text {nd }}$

\section{$5.4 \quad$ Study Two - Discussion}

Are the clusters effectively the same? This is difficult to quantify. The clusters are clearly not identical: some of the descriptive statistics in Tables 5-11 are statistically significantly different from one presentation to the next at a high level of significance. But are those differences meaningful? As an extreme, $99 \%$ of learners in the Nearly There cluster first presentation of MOOC1 completed more than four assessments, compared to $100 \%$ in the second (see bottom Table 9), and this difference is significant at greater than the 0.001 level. It seems hard to argue that this is a meaningful difference between clusters of learner behaviours on subsequent presentations of the same MOOC.

Standard hypothesis testing, as we have carried out here, seeks to reject the null hypothesis of no difference between the two groups. This is not the same as testing whether there is no difference: that is the domain of testing for equivalence. To test for equivalence, one has to first define the range of results that would be considered effectively the same, and then test whether the results fall inside some 
(2015). Consistent commitment: Patterns of engagement across time in Massive Open Online Courses (MOOCs). Journal of Learning Analytics, 2(3), 55-80. http://dx.doi.org/10.18608/jla.2015.23.5

confidence interval based on that range. The "cluster characteristics" column is our suggestion for a range that is effectively the same - and all the data fall within this range.

For instance, the precise percentage of learners in the Samplers cluster (Table 5) who leave a comment is different in a statistically significantly way from one presentation of a MOOC to a subsequent one $(15 \%$ on MOOC1's first presentation, $11 \%$ on the second). However, it is fairly low in all cases $(<20 \%)$, and this (and other characteristics) distinguishes this cluster from the other clusters. The clusters are practically similar between MOOCs and between one presentation of a MOOC and the subsequent one.

Unfortunately, as already discussed, the dataset available for these studies does not contain any outcome measures (such as assessment results or survey responses) that would provide an independent comparison.

The similarity in the descriptive statistics from the more than 30,000 learners who engaged with the two presentations of MOOC1 and MOOC4 indicates that these seven clusters are stable across presentations. It is not possible to test this directly, as the assessment and survey data cannot be aligned with activity data. However, there is no evidence that these clusters change meaningfully as learners gain more experience in online learning.

\section{CONCLUSION}

\subsection{Limitations of this Approach to Cluster Analysis}

This work has followed and extended the original methodology of Kizilcec et al. It has yielded some potentially useful insights for practice and for future research (see subsequent sections). However, there are significant limitations to the approaches taken by both this work and the work it builds on.

Both approaches entailed significant processing and data reduction and choices around the cluster analysis. One significant practical advantage of coding weekly behaviour in to a single measure is that it enables analysts to inspect individual patterns at a glance in a way impossible if the direct logfile data is used. However, this makes data unavailable for clustering: for instance, it would be impossible to distinguish learners who tended to work in one burst a week from learners who studied in a more spreadout pattern. The approach taken to the cluster analysis in both approaches is rather simplistic. It is not obvious that $k$-means is the best clustering algorithm in this context - not least because it requires what may be an arbitrary decision to be made by the analyst about how many clusters to extract.

It seems highly likely that the patterns that emerged in the final clusters reflect, at least to some degree, the choices made in this process. Kizilcec et al. coded weekly behaviour based on whether or not learners engaged with content or did the assessment, and compressed this in to a single dimension before clustering: they found four clusters that reflected the four logical possibilities (Sampling - low engagement with content; Auditing - high engagement with content; Disengaging - low engagement with assessments; Completing - high engagement with assessment). The adapted method in this paper 
(2015). Consistent commitment: Patterns of engagement across time in Massive Open Online Courses (MOOCs). Journal of Learning Analytics, 2(3), 55-80. http://dx.doi.org/10.18608/jla.2015.23.5

added data about commenting, and found clusters where commenting behaviour was a distinguishing feature. Rather than compressing the weekly data in to a single dimension, this paper used a dimension for each week, and duly found clusters where behaviour changed over the weeks.

That is not to say that these patterns do not exist in the data: they almost certainly do. However, they do not emerge from the data without influence from the choices made in the analysis. Accordingly, we wish to be very modest about the clusters from our own analysis. They are far from a correct, complete, or robust analysis of the participation patterns of learners in a MOOC. We claim only that they provide an informative view of learner behaviour, which has some potentially valuable implications for practice. However, two patterns of behaviour do seem to emerge robustly from cluster analysis of learner behaviour on MOOCs: samplers, who visit only briefly; and completers, who fully engage with the course.

\subsection{Implications for Practice}

The key characteristic of learning analytics, as distinct from the general category of quantitative educational research, is a direct concern with improving learning and learning environments. "The key step is "closing the loop" by feeding back [...] to learners through one or more interventions" (Clow, 2012). How can this analysis achieve that?

The clusters identified here can help inform a range of strategies for intervention and improvement. As these clusters have now been found on a range of presentations of MOOCs from different universities and covering different subjects, educators can be confident that they are stable as long as the learning design (eight-week courses with weekly assessment) and pedagogy (conversational learning) remain constant.

Providing previews of course material would allow Samplers to make a more informed decision about whether to register in the first place.

The four clusters in which learners engage solidly but fail to complete - the Strong Starters, Returners, Mid-way Dropouts, and particularly the Nearly There cluster - are precisely those learners that educators would want to focus on to improve completion. This data analysis suggests that there are several points at which learners may leave a course, and these may be dealt with in different ways.

Discussion steps set up for latecomers could be used to support those who fall behind at the start, while sign-up pages could draw attention to the difficulties encountered by learners who move through the course out of step with the cohort. These pages might suggest that potential learners return later and register for a subsequent presentation. Free-text survey comments on FutureLearn MOOCs that have run more than once show that some learners return to subsequent presentations in order to finish working through the material with a group - even though they already have access to the same content because they registered on the original presentation. 
(2015). Consistent commitment: Patterns of engagement across time in Massive Open Online Courses (MOOCs). Journal of Learning Analytics, 2(3), 55-80. http://dx.doi.org/10.18608/jla.2015.23.5

The course week is an artificial distinction that imposes a weekly format on the learning design of the course. In doing so, it makes the decision to move on to the next week of the course appear more significant than the decision to move on to the next step. Changes to learning design could provide bridges between course weeks, stressing links between these weeks, and pointing learners forward. This might reduce the drop-off experienced by these courses, particularly at the ends of Week 1 and Week 2 .

The two most clearly successful clusters - the Late Completers and the Keen Completers - also afford actionable insights. In the context of FutureLearn, at least, they appear to provide some small degree of vindication of the extensive and structured use of discussion comments.

\subsection{Implications for Future Research}

These clusters could be used to support qualitative research into learner engagement. In particular, it would be useful for practice to identify what prompts Keen Completers to engage to such an extent, and what factors influence drop out by the Nearly There cluster.

However, these results suggest that this approach to clustering data from learners on MOOCs has been pursued as far as is defensible. Neither the Kizilcec et al. approach nor the adaptation of it in this paper appears to be particularly robust. Future work should explore more rigorous and sophisticated approaches to analyzing learner behaviour, including less reductive data preparation and coding, other clustering methods (e.g., hierarchical clustering approaches), similarity measures other than Euclidean distance (e.g., Levenshtein distance on textual profiles), and so on. Other data may well prove useful. For instance, it is well known that simply counting forum contributions can be misleading if one is interested in the contribution to learning. A more robust set of patterns would be potentially very useful for practitioners to target on-course support.

This work has explored patterns of individual learner behaviour within a MOOC, and on subsequent presentations of the same MOOC. With a more robust classification system for learner behaviour, it would be interesting to explore learner behaviour in different MOOCs, which might shed light on the stability or otherwise of such behaviours and on what associations there may be between MOOC characteristics and learner behaviours.

\subsection{Final Remarks}

As open offerings, for some values of "open," MOOCs afford a wide range of engagement patterns. Two have emerged consistently from this work and previous research: the sampling behaviour employed by people who visit a course briefly, and the fully engaged behaviour employed by learners who engage with all aspects of a course. The studies reported here suggest that both these and other patterns of engagement remain stable across presentations of a course, when key elements of pedagogy and learning design remain constant. 
(2015). Consistent commitment: Patterns of engagement across time in Massive Open Online Courses (MOOCs). Journal of Learning Analytics, 2(3), 55-80. http://dx.doi.org/10.18608/jla.2015.23.5

\section{ACKNOWLEDGEMENTS}

We would like to thank the FutureLearn team for giving us access to the activity data used in this analysis.

\section{REFERENCES}

Bohannon, J. (2014). Replication effort provokes praise-and "bullying" charges. Science, 344(6186). http://dx.doi.org/10.1126/science.344.6186.788

Clow, D. (2012). The learning analytics cycle: Closing the loop effectively. Proceedings of the 2nd International Conference on Learning Analytics \& Knowledge (LAK '12), 134-138. http://dx.doi.org/10.1145/2330601.2330636

Clow, D. (2013). MOOCs and the funnel of participation. Proceedings of the 3rd International Conference on Learning Analytics and Knowledge (LAK '13), 185-189. http://dx.doi.org/10.1145/2460296.2460332

Daniel, J. (2012). Making sense of MOOCs: Musings in a maze of myth, paradox and possibility. Journal of Interactive Media in Education, 2012(3). http://dx.doi.org/10.5334/2012-18

Downes, S. (2012). Connectivism and connective knowledge: Essays on meaning and learning networks. Retrieved from http://www.downes.ca/files/books/Connective_Knowledge-19May2012.pdf

Downes, S. (2014, 21 March). Like reading a newspaper (Web log post). Retrieved from http://halfanhour.blogspot.co.uk/2014/03/like-reading-newspaper.html

Ferguson, R., Clow, D., Beale, R., Cooper, A. J., Morris, N., Bayne, S., \& Woodgate, A. (2015). Moving through MOOCS: Pedagogy, learning design and patterns of engagement. Proceedings of the $10^{\text {th }}$ European Conference on Technology Enhanced Learning (EC-TEL '15), 70-84. http://dx.doi.org/10.1007/978-3-319-24258-3_6

Jordan, K. (2014a). Initial trends in enrolment and completion of massive open online courses. The International Review of Research in Open and Distance Learning, 15(1), 133-160. Retrieved from http://www.irrodl.org/index.php/irrodl/article/view/1651

Jordan, K. (2014b). MOOC completion rates: The Data. Retrieved February, 2, 2016, from http://www.katyjordan.com/MOOCproject.html

Kizilcec, R., Piech, C., \& Schneider, E. (2013). Deconstructing disengagement: Analyzing learner subpopulations in massive open online courses. Proceedings of the $3^{\text {rd }}$ International Learning Analytics \& Knowledge Conference (LAK '13), 170-179. http://dx.doi.org/10.1145/2460296.2460330

Kop, R., Fournier, H., \& Sui Fai, J. M. (2011). A pedagogy of abundance or a pedagogy to support human beings? Participant support on Massive Open Online Courses. The International Review of Research in Open and Distance Learning, 12(7), 74-93. Retrieved from http://www.irrodl.org/index.php/irrodl/article/view/1041/2025 
(2015). Consistent commitment: Patterns of engagement across time in Massive Open Online Courses (MOOCs). Journal of Learning Analytics, 2(3), 55-80. http://dx.doi.org/10.18608/jla.2015.23.5

Laurillard, D. (2002). Rethinking university teaching: A conversational framework for the effective use of learning technologies (2nd ed.). London: RoutledgeFalmer.

Littlejohn, A. (2013). CEMCA ed tech notes: Understanding Massive Open Online Courses. Retrieved from http://cemca.org.in/ckfinder/userfiles/files/EdTech Notes 2_Littlejohn_final_1June2013.pdf

Milligan, C., Littlejohn, A., \& Margaryan, A. (2013). Patterns of engagement in connectivist MOOCs. Journal of Online Learning and Teaching, 9(2). Retrieved from http://jolt.merlot.org/vol9no2/milligan_0613.htm

Pask, G. (1976). Conversation theory: Applications in education and epistemology. New York: Elsevier.

Ferguson, R. \& Sharples, M. (2014). Innovative pedagogy at massive scale: Teaching and learning in MOOCs. Proceedings of the $9^{\text {th }}$ European Conference on Technology Enhanced Learning (EC-TEL '14), 98-111. http://dx.doi.org/10.1007/978-3-319-11200-8_8

Siemens, G. (2005). Connectivism: A learning theory for the digital age. International Journal of Instructional Technology and Distance Learning, 2(1). Retrieved from http://www.itdl.org/journal/jan_05/article01.htm

Siemens, G. (2012, 25 July). MOOCs are really a platform (Web log post). Retrieved from http://www.elearnspace.org/blog/2012/07/25/moocs-are-really-a-platform/

Society for Learning Analytics Research. (2011). Open learning analytics: An integrated \& modularized platform (White Paper). Retrieved from http://solaresearch.org/OpenLearningAnalytics.pdf 